\title{
Thermal Characterization of Pozzolanic Activity of Hydrated Cement System Modified by Silica Based Industrial Waste
}

\author{
Faatima Zahra Ahmat Asim ${ }^{1}$, and Norsuzailina Mohamed Sutan ${ }^{2}$ \\ ${ }^{1,2}$ Department of Civil Engineering, Faculty of Engineering, Universiti Malaysia Sarawak, \\ Kota Samarahan 94300, Sarawak, Malaysia. \\ ${ }^{1}$ Email: faatimazahra88@yahoo.com, 22mail: msnorsuzailina@feng.unimas.my
}

\begin{abstract}
This study investigates the potential of using silica based industrial waste specifically waste calcined clay (WCC) from ceramic industry as partial cement replacement. Pozzolanic activity characterization was done by using thermal and mechanical characterization techniques namely Thermal Gravimetric Analysis (TGA) and Compressive Strength Test (CS), respectively. Finely grounded waste vase of varying particles sizes range from less than $75 \mu \mathrm{m}, 75 \mu \mathrm{m}$ and $150 \mu \mathrm{m}$ were used as $10 \%, 20 \%$, and $30 \%$ cement replacements with 0.45 water to cement ratio (w/c). First, progression of CS from day 1 to 28 of WCC modified mortar and unmodified cement mortar (UCM) was monitored as an indirect indication of pozzolanic activity. It was found that 75 WCC10\% performed higher 28 day compressive strength compared to unmodified cement mortar (UCM). To further confirm the result, TGA characterization of Calcium Silicate Hydrate $(\mathrm{C}-\mathrm{S}-\mathrm{H})$ and Calcium Hydroxide $(\mathrm{CH})$ as pozzolanic activity indicator was done on WCC modified cement pastes in comparison to unmodified cement paste (UCP). TGA analysis has shown the pozzolanic activity indicated by the decrease of $\mathrm{CH}$ and the increase of C-S-H in WCC modified cement paste. Based on this study, WCC possesses pozzolanic characteristic which is the main criteria to be qualified as an effective material as partial cement replacement.
\end{abstract}

Keywords: Waste calcined clay, cement replacement, Thermal gravimetric analysis (TGA), compressive strength test (CS)

\section{Introduction}

Production of unsustainable cement that emits $\mathrm{CO}_{2}$ has lead researchers to find several sustainable alternatives to partially replace it if not all $[1,2]$. This is why the terms such as supplementary, partial cement replacements, mineral admixtures and geo polymer emerges in the recent development on cement and concrete research. One of the ways to reduce cement dependency is by using industrial by-product or waste as partial cement replacement in concrete production. This serves as two edged sword whereby it can reduce the negative environmental impact caused by the waste and cement production [3]. One of the industrial wastes that has not been fully utilized, is waste from ceramic industry called calcined clay.

Historically, structures such as water tank, walls and bridges have been constructed using thermally activated clay and lime mortars before the invention of Portland cement. The Romans used crushed tiles as cementitious material other than volcanic ash since they discover that the combination of lime and calcined earths could form strong cementing materials [4-6].Several studies have been

Manuscript History:

Received 4 March, 2015, Revised 22 March, 2015, Accepted 23 March, 2015, Published 30 April, 2015

e-ISSN 2289-7771

Copyright $\odot 2015$ JASPE 
conducted on the use of waste calcined clay brick and calcined china clay or calcined kaolin as cement replacement in concrete production [6-9]. The results showed that 10\%-20\% of WCC improve the mechanical properties of concrete due to its high pozzolanic reactivity. Any siliceous or siliceous and aluminous material that has no cementitious quality but can react with lime in the presence of water at normal temperature to from cementitious compound are categorized as pozzolan [10]. To date there is limited understanding on potential of waste vase from ceramic industry to be used as partial cement replacement. Since the calcined earthenware is commonly produced from blended kaolin and soil, hypothetically, it possesses pozzolanic properties that would be potentially suitable for reuse as partial cement replacement. Therefore, the motivation of this study is to investigate the pozzolanic activity of WWC modified cement paste and mortar by focusing on particle size effect on the activity.

\section{Materials and methods}

\subsection{Materials}

WCC used as cement replacements was waste vase collected from Naga Emas Ceramic Ind. Sdn. Bhd. The waste vase was cleaned with water to remove dirt and washable contaminants. It was then crushed into smaller piece and finely grounded to three finer particle sizes of $150 \mu \mathrm{m}, 75 \mu \mathrm{m}$, and smaller than $75 \mu \mathrm{m}$. Table 1 shows the chemical composition of WCC obtained from X-ray fluorescence (XRF) analysis. Cement used was Ordinary Portland Cement (OPC) (ASTM Type 1 recognized by ASTM C150) manufactured by Cahaya Mata Sarawak Cement Sdn. Bhd.(CMS) and it exceeds the quality requirements specified in the Malaysian Standard MS 522: Part 1: 1989 Specifications for OPC. The raw materials are clinker (90\%), limestone (5\%) and gypsum (5\%). The physical properties and chemical compositions of the OPC are shown in Table 1. Water used in mixing for this study was regular water tap. Meanwhile, sand used as a fine aggregate was natural river sand. 
Table 1. Physical properties and chemical composition of OPC and WCC

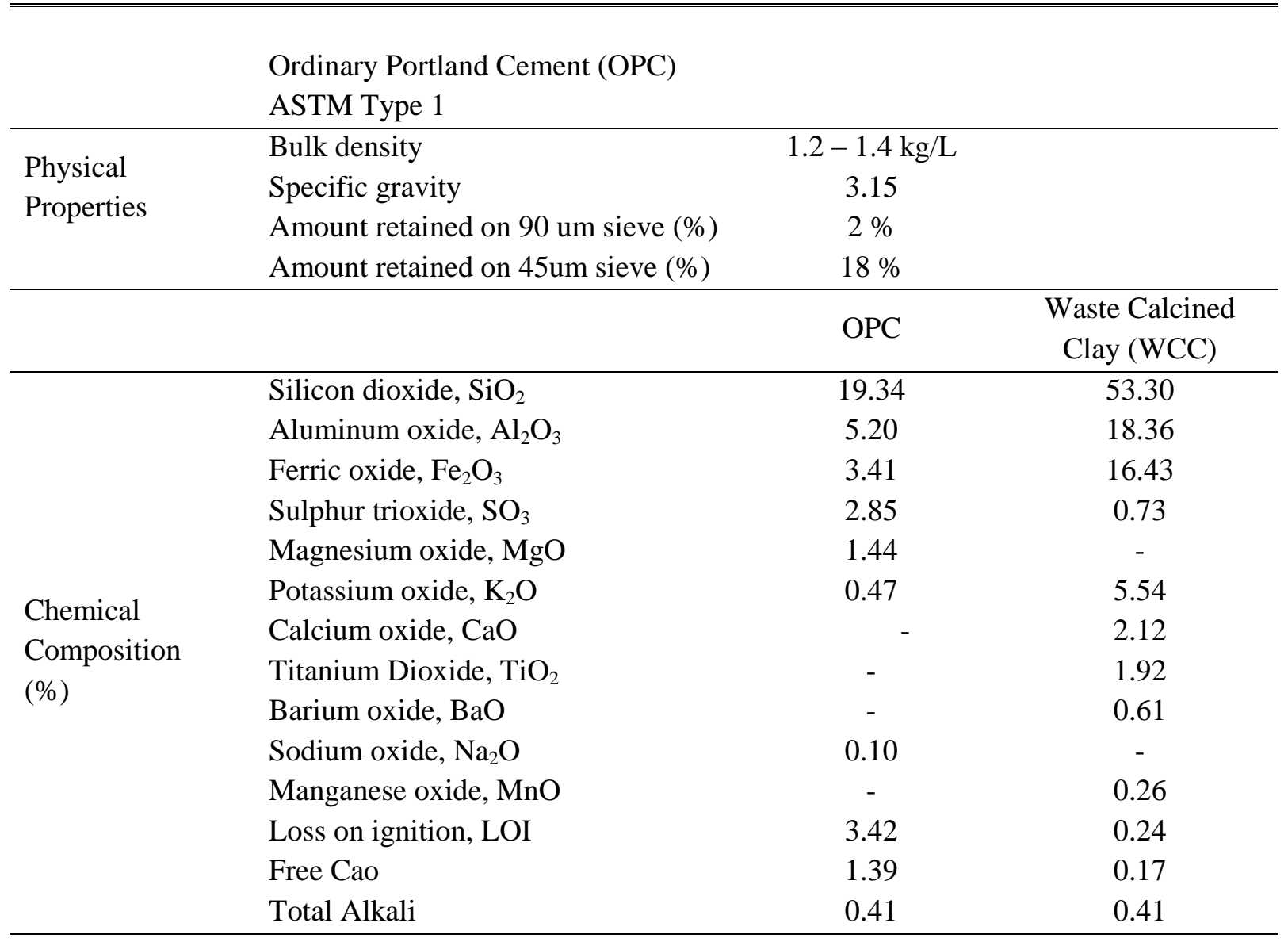

\subsection{Sample preparation for Compressive Strength (CS) test}

The mix proportion for mortar was set at (water: sand: cement) 1:0.6(c/s):0.5(w/c) for all specimens that were casted into $150 \mathrm{~mm}$ cubes for compressive strength (CS) tests. All specimens were wet cured in the concrete laboratory at Universiti Malaysia Sarawak 28 days. 28-day CS test was performed according to BS 1881-116 (1983) on $150 \mathrm{~mm}$ cubes samples [11]. It was used to determine the maximum compressive load that a sample can carry per unit area. The compressive strength gives the overall picture of the quality of mortar as it hydrates. Each strength value was the average of the strength of three specimens [11]. All samples were prepared using the mix proportion as shown in Table 2. 
Table 2.Mix proportions by weight per 50 x $50 \times 50 \mathrm{~mm}$ mortar cubes

\begin{tabular}{lllll}
\hline Name & Water $(\mathbf{g})$ & OPC $(\mathbf{g})$ & Sand $(\mathbf{g})$ & WCC $(\mathbf{g})$ \\
\hline \hline UCM & 39.07 & 86.83 & 144.72 & - \\
$150 \mu \mathrm{mWCC} 10 \%$ & 39.07 & 78.15 & 144.72 & 8.68 \\
$150 \mu \mathrm{mWCC} 20 \%$ & 39.07 & 69.47 & 144.72 & 17.37 \\
$150 \mu \mathrm{mWCC} 30 \%$ & 39.07 & 60.79 & 144.72 & 26.05 \\
$75 \mu \mathrm{mWCC} 10 \%$ & 39.07 & 78.15 & 144.72 & 8.68 \\
$75 \mu \mathrm{mWCC} 20 \%$ & 39.07 & 69.47 & 144.72 & 17.37 \\
$75 \mu \mathrm{mWCC} 30 \%$ & 39.07 & 60.79 & 144.72 & 26.05 \\
$<75 \mu \mathrm{mWCC} 10 \%$ & 39.07 & 78.15 & 144.72 & 8.68 \\
$<75 \mu \mathrm{mWCC} 20 \%$ & 39.07 & 69.47 & 144.72 & 17.37 \\
$<75 \mu \mathrm{mWCC} 30 \%$ & 39.07 & 60.79 & 144.72 & 26.05 \\
\hline \hline
\end{tabular}

\subsection{Sample preparation for Thermal Gravimetric Analysis (TGA)/ Derivative Thermo Gravimetry (DTG) characterization technique}

The mix proportion for cement paste was set at 0.45 water to cement ratio $(\mathrm{w} / \mathrm{c})$ for all specimens that were casted into Universal Container 30ml, Diameter 28x85mm for TGA)/ DTG analysis. Three particle sizes of $150 \mu \mathrm{m}, 75 \mu \mathrm{m}$ and lower than $75 \mu \mathrm{m}$ finely grounded WCC were used to replace $10 \%, 20 \%$, and $30 \%$ of OPC. After 28 days, the specimen was removed from tube, cut in the middle and finely grounded into powder. All specimens were cured in the concrete laboratory at Universiti Malaysia Sarawak at daily room temperature (T) and relative humidity $(\mathrm{RH})$ in the range of $18-28^{\circ} \mathrm{C}$ and $65-90 \%$, respectively. The fine powder (passing $75 \mu \mathrm{m}$ ) was prepared and analyzed using TGA at day 28. Ethanol was used to discontinue the hydration process of these samples.

In this study, TGA/DTG measurements were carried out on 5-10 mg powder samples of control mortar and modified mortar using a TA Analyzer (Mettler-Toledo TGA/SDTG 851e). This combined thermal characterization technique was set up to run samples in nitrogen with a flow rate of $100 \mathrm{~mL} / \mathrm{min}$ and a constant heating rising of $20^{\circ} \mathrm{C} / \mathrm{min}$ up to $1000^{\circ} \mathrm{C}$. Thermal decomposition of each samples occurred in a programmed temperature range of $200-1000 \mathrm{C}$. The continuous weight loss and temperature were recorded and analyzed to determine the following TGA parameters: thermal degradation rate (\% weight loss $/ \mathrm{min}$ ), initial degradation temperature and residual weight at $200^{\circ} \mathrm{C}$.

\section{Results and Discussions}

\subsection{Compressive strength of mortar}

Figure 1 shows the 28-day compressive strength of all samples. Generally the compressive strength of modified and non-modified mortar increase with respect to time [1]. It can be seen in Figure 1 that WCC modified mortar of $75 \mu \mathrm{m}$ particle size of $10 \%$ cement replacement achieved highest compressive strength compared to all samples. The result indirectly indicated that WCC with particle size of $75 \mu \mathrm{m}$ have higher pozzolanic reactivity compared with $150 \mu \mathrm{m}$ and $<75 \mu \mathrm{m}$ in 28 days. It has been established from previous pozzolanic activity studies that particle size plays significant role for pozzolanic material to react. As mentioned before, pozzolanic reaction will 
produce fine hydrated phase of C-S-H gels that will densify the microstructure hence increased the compressive strength. The larger the surface area of the pozzolan, the more reactive it will be. On the other hand, the tendency for agglomeration that prevents full pozzolanic reaction will increase as the particle size gets smaller $[12,13]$ This is reflected by the lesser 28-day compressive strength of WCC samples with particle size $<75 \mu \mathrm{m}$. Based on this result, optimum mix to produce the maximum pozzolanic activity is $75 \mu \mathrm{mWWC}$ with $10 \%$ cement replacement that was used for further confirmation with TGA analysis specifically on the pozzolanic activity.

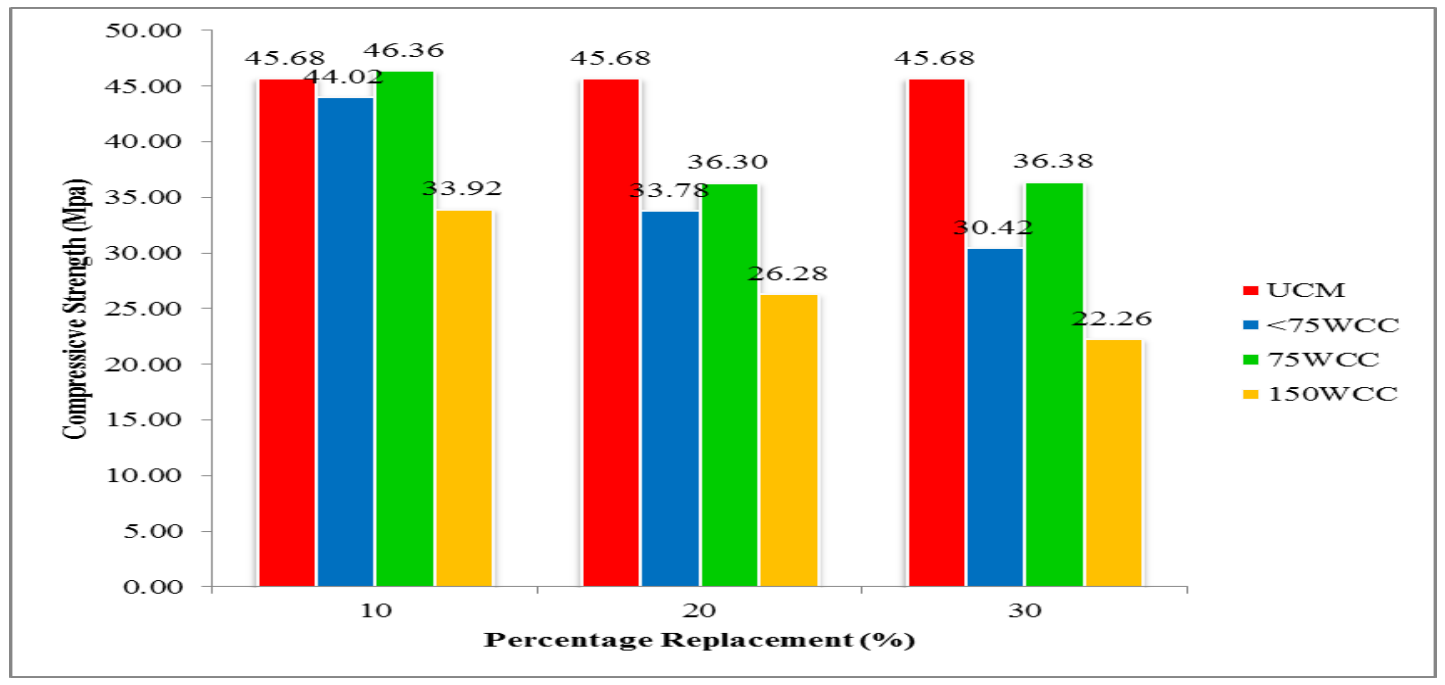

Figure 1. Compressive strength various size of waste calcined clay with UCM at 28 days.

\subsection{Thermal Gravimetric Analysis (TGA)/ Derivative Thermo Gravimetry (DTG)}

Pozzolanic activity of $75 \mu \mathrm{mWWC} 10 \%$ cement paste and UCP was further investigated using Thermal Gravimetric Analysis (TGA)/ Derivative Thermo Gravimetry (DTG). Figure 2(a) and (b) shows the TGA/DTG mass loss graph of UCP and $75 \mu \mathrm{mWCC} 10 \%$ samples, respectively. Both graphs show a gradually decreasing pattern and this explained that the hydration process rate for both samples. It can be observed from the graphs of that there are three stages of mass loss. The first stage of weight loss, located at 30 to $200^{\circ} \mathrm{C}$, is the result of dehydration of several hydrates $(\mathrm{C}-\mathrm{S}-\mathrm{H}$, ettringite, carboaluminates, etc.) This loss of water is mainly due to the dehydration of the C-S-H. The second major mass loss, observed at $450-500{ }^{\circ} \mathrm{C}$, correspond to the dehydroxylation of portlandite $(\mathrm{CH})$, another hydration product. The third mass loss appears at $750^{\circ} \mathrm{C}$ and corresponds to the decarbonation of calcium carbonate $\left(\mathrm{CaCO}_{3}\right)$ coming from clinker and the filler [14, 15]. It can be clearly seen from the graph that $\mathrm{CH}$ has significantly reduced in $75 \mu \mathrm{mWCC} 10 \%$ sample compared to UCP sample indicating the pozzolanic reaction has occurred that produced more C-S-H. This result corroborates the 28-day compressive strength test result that confirmed the optimum mix as $75 \mu \mathrm{m}$ WWC with $10 \%$ cement replacement. 


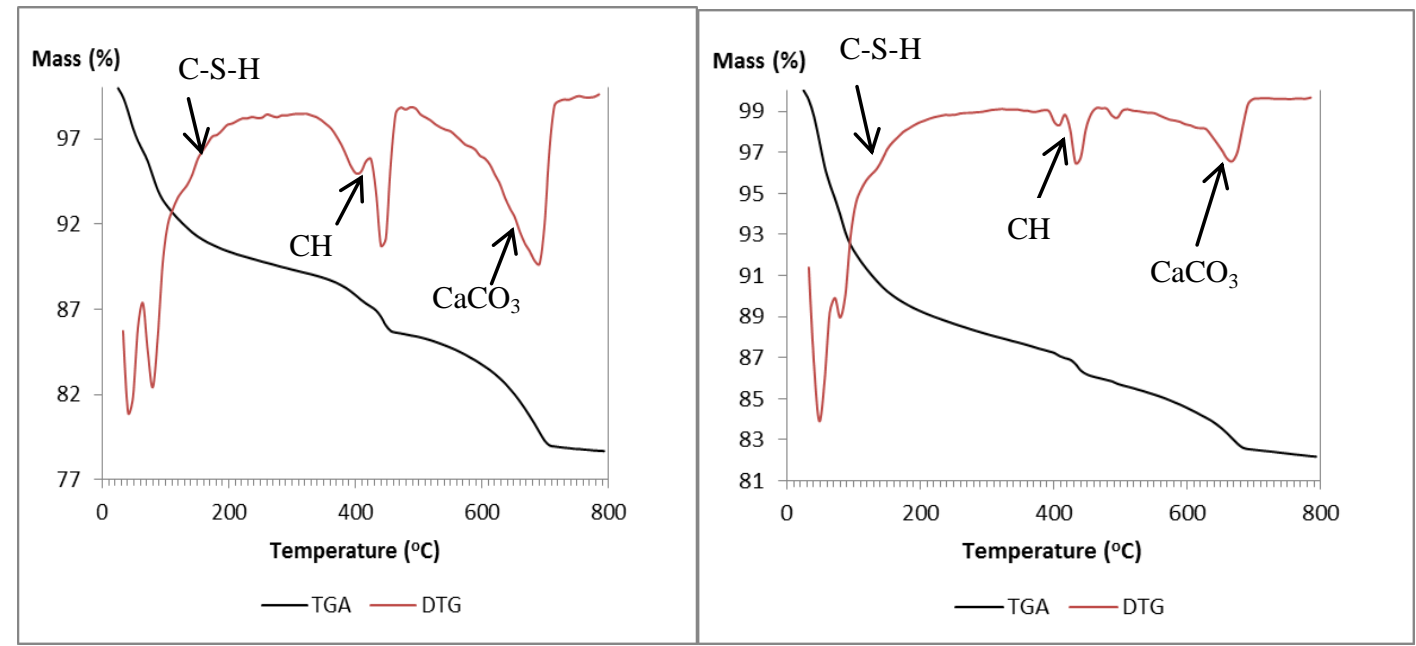

(a)

(b)

Figure 2. TGA result for (a) UCP and (b) $75 \mu \mathrm{mWCC} 10 \%$ samples at day-28.

\section{Conclusions}

In conclusion, WCC modified cement system has shown pozzolanic characteristic reflected in higher 28-day compressive strength than UCM. Based on this study, the optimum mix is $75 \mu \mathrm{m}$ WWC with $10 \%$ cement replacement. TGA/DTG analysis has shown the pozzolanic activity indicated by the decrease of $\mathrm{CH}$ and the increase of $\mathrm{C}-\mathrm{S}-\mathrm{H}$ in WCC modified cement paste. This result corroborates the 28-day compressive strength test result that confirmed the optimum mix as $75 \mu \mathrm{m}$ WWC with $10 \%$ cement replacement. Based on this study, WCC possesses pozzolanic characteristic which is the main criteria to be qualified as an effective material as partial cement replacement. Utilizing WCC as cement replacement is not only can improve concrete properties but it can provide the means of industrial waste material disposal and reduce the environmental negative impact of cement production.

\section{Acknowledgments}

The authors wish to acknowledge Ministry of Education and Universiti Malaysia Sarawak for supporting this work under ERGS/TK04(02)/1011/2013 (08) and RACE/c(1)/1108/2013(16) grants.

\section{References}

[1] M. O'Farrell, S. Wild, and B. B. Sabir, Pore size distribution and compressive strength of waste clay brick mortar,Cem. Concr. Compos., vol. 23, no. 1, pp. 81-91, Feb. 2001.

[2] D. Vu, P. Stroeven, and V. . Bui, Strength and durability aspects of calcined kaolin-blended Portland cement mortar and concrete,Cem. Concr. Compos., vol. 23, no. 6, pp. 471-478, Dec. 2001.

[3] B. Arnon and M. Sidney, Sustainability of Concrete. Taylor \& Francis e-Library, 2012.

[4] P. S. L. Souza and D. C. C. Dal Molin, Viability of using calcined clays, from industrial by-products, as pozzolans of high reactivity,Cem. Concr. Res., vol. 35, no. 10, pp. 1993-1998, Oct. 2005.

[5] P. Bhimani, Performance of Concrete with China Clay ( Kaolin ) Waste,vol. 2, no. 3, pp. 49-54, 2013. 
[6] R. D. Toledo Filho, J. P. Gonçalves, B. B. Americano, and E. M. R. Fairbairn, Potential for use of crushed waste calcined-clay brick as a supplementary cementitious material in Brazil," Cem. Concr. Res., vol. 37 , no. 9, pp. 1357-1365, Sep. 2007.

[7] A. Naceri and M. C. Hamina, Effects Of Pozzolanic Admixture ( Waste Bricks ) On Mechanical Response Of Mortar, vol. 21, no. 1, pp. 1-8, 2008.

[8] S. Wild, Sulphate Resistance Of Mortar, Containing Ground Brick Clay Calcined At Different Temperatures, vol. 27, no. 5, pp. 697-709, 1997.

[9] R. Fernandez, F. Martirena, and K. L. Scrivener, The origin of the pozzolanic activity of calcined clay minerals: A comparison between kaolinite, illite and montmorillonite, Cem. Concr. Res., vol. 41, no. 1, pp. 113-122, Jan. 2011.

[10] ASTM C595, Standard Specification for Blended Hydraulic Cements, 1998.

[11]BS 1881-116(1983) Testing concrete Method for determination of compressive strength of concrete cubes.

[12] M. Juenger and S. Taylor-lange, The Use Of Impure Clays As Materials Calcined Clays, Kansas State University, 2013, pp. 1-14.

[13] V. Viswabaskaran, F. D. Gnanam, and M. Balasubramanian, Mullitisation behaviour of calcined clay alumina mixtures, vol. 29, pp. 561-571, 2003.

[14] A. Tironi, M. a. Trezza, A. N. Scian, and E. F. Irassar, Assessment of pozzolanic activity of different calcined clays,Cem. Concr. Compos., vol. 37, pp. 319-327, Mar. 2013.

[15]L. Soriano, J. Monzó, M. Bonilla, M. M. Tashima, J. Payá, and M. V. Borrachero, Effect of pozzolans on the hydration process of Portland cement cured at low temperatures,Cem. Concr. Compos., vol. 42, pp. 4148, Sep. 2013.

\section{Authors}

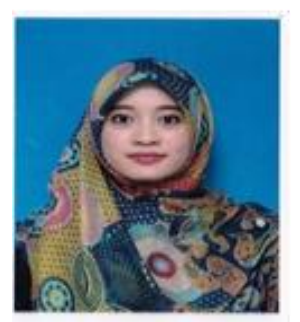

\section{Faatima Zahra Ahmat Asim}

Faatima Zahra Ahmat Asim was a student in the Department of Civil Engineering, Faculty of Engineering, Universiti Malaysia Sarawak (UNIMAS). She has developed an interest in concrete material research

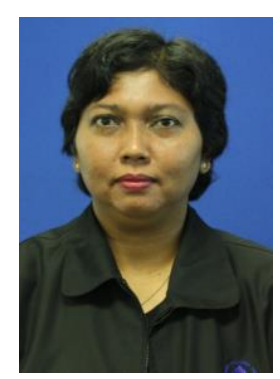

\section{Norsuzailina Mohamed Sutan}

Norsuzailina Mohamed Sutan is a senior lecturer in the Department of Civil Engineering, Faculty of Engineering, Universiti Malaysia Sarawak (UNIMAS).She obtained her PhD from UNIMAS and her research interest is material characterizations and supplementary cementitious materials. 